\title{
Fetal distress and birth scores in newborn infants
}

\author{
S. W. DE SOUZA, R. W. JOHN, B. RICHARDS, and R. D. G. MILNER \\ From the Department of Child Health, University of Manchester, and the Department of Computation, \\ University of Manchester Institute of Science and Technology
}

\begin{abstract}
De Souza, S. W., John, R. W., Richards, B., and Milner, R. D. G. (1975). Archives of Disease in Childhhod, 50, 920. Fetal distress and birth scores in newborn infants. The relation between fetal distress and the subsequent condition at birth was studied in 2791 pregnancies. Fetal distress was defined as a heart rate $>160$ or $<120 / \mathrm{min}$ between uterine contractions, with or without meconium-stained liquor. Infants of 28 to 42 weeks' gestational age were examined at 1 and 5 minutes after birth when the heart rate, respiration, and skin colour were recorded. Birth scores of 0,1 , or 2 were given respectively if respirations were absent, gasping, or regular; if the heart rate was undetectable, $<100 / \mathrm{min}$, or $>100 / \mathrm{min}$; and if the colour was white, blue, or pink. Fetal distress was associated with low birth scores in infants at 1 and 5 minutes of age. Among those who had not suffered fetal distress a significantly greater proportion of preterm infants had low birth scores compared with term or post-term infants at 5 minutes of age.

Infants did not score equally for colour, heart rate, and respiration at 1 and 5 minutes of age. Colour usually gave a birth score of 5 and heart rate was recordable when infants scored 0 for colour and respiration. The reduction in birth scores was greater in the presence of meconium-stained liquor and abnormal fetal heart rate than meconium-stained liquor alone; the latter being an early sign of fetal distress. Since fetal distress was not diagnosed by conventional methods in 93 term infants who probably suffered prenatal asphyxia, more sophisticated techniques are necessary for an accurate assessment of fetal condition during labour.
\end{abstract}

Gross disturbances of fetal heart rate during labour, especially when accompanied by the passage of meconium, are accepted signs of fetal asphyxia (Schulte, 1925; McCall and Fulsher, 1953; Nesbitt, 1955; Desmond et al., 1957; Walker, 1959; Wood et al., 1967; Kubli et al., 1969; Hobel, 1971; Beard and Simons, 1971; Tipton and Shelley, 1971). These clinical observations are supported by experimental studies in animals (Born, Dawes, and Mott, 1956; Dawes et al., 1960; Hobel et al., 1970; Adamsons, Beard, and Myers, 1970; James et al., 1972; Adamsons and Myers, 1973). Fetuses that have shown such signs of distress are likely to be in a poor condition at birth and to need special attention. While sophisticated monitoring techniques offer the best chances of detecting distress in a particular fetus they are not available to all. The present study was undertaken to analyse the relation between fetal distress as it is conventionally

Received 18 April 197j. detected by the nursing staff, and the subsequent condition of the infant at birth.

\section{Subjects and methods}

The 2791 infants on whom the study was based were born during 1971 at St. Mary's Hospital, Manchester. All were single pregnancies. Gestational age was taken as the number of completed weeks from the first day of the mother's last menstrual period and varied between 28 and 44 weeks. Infants of 28-36 weeks' gestational age were defined as preterm, those of 37-41 weeks as term, and those of $\mathbf{4 2 - 4 4}$ weeks as post-term. During labour the fetal heart rate was recorded by auscultation by a midwife at regular intervals of about 15 minutes. Fetal heart rate was defined as abnormal if it was $<120$ or $>160 / \mathrm{min}$. The presence or absence of meconium-stained liquor was also recorded. Fetal distress was defined in three ways: as abnormal heartrate plus meconium-stained liquor, abnormal heart rate, or as meconium-stained liquor alone. The heart rate, respiration, and skin colour were recorded at 1 and 5 minutes after birth. The scores of 0,1 , or 2 were given, respectively, if the respirations were absent, 
TABLE I

Effects of gestational age on birth scores of infants with or without abnormal fetal heart rate (AHR) and meconium-stained liquor (MSL)

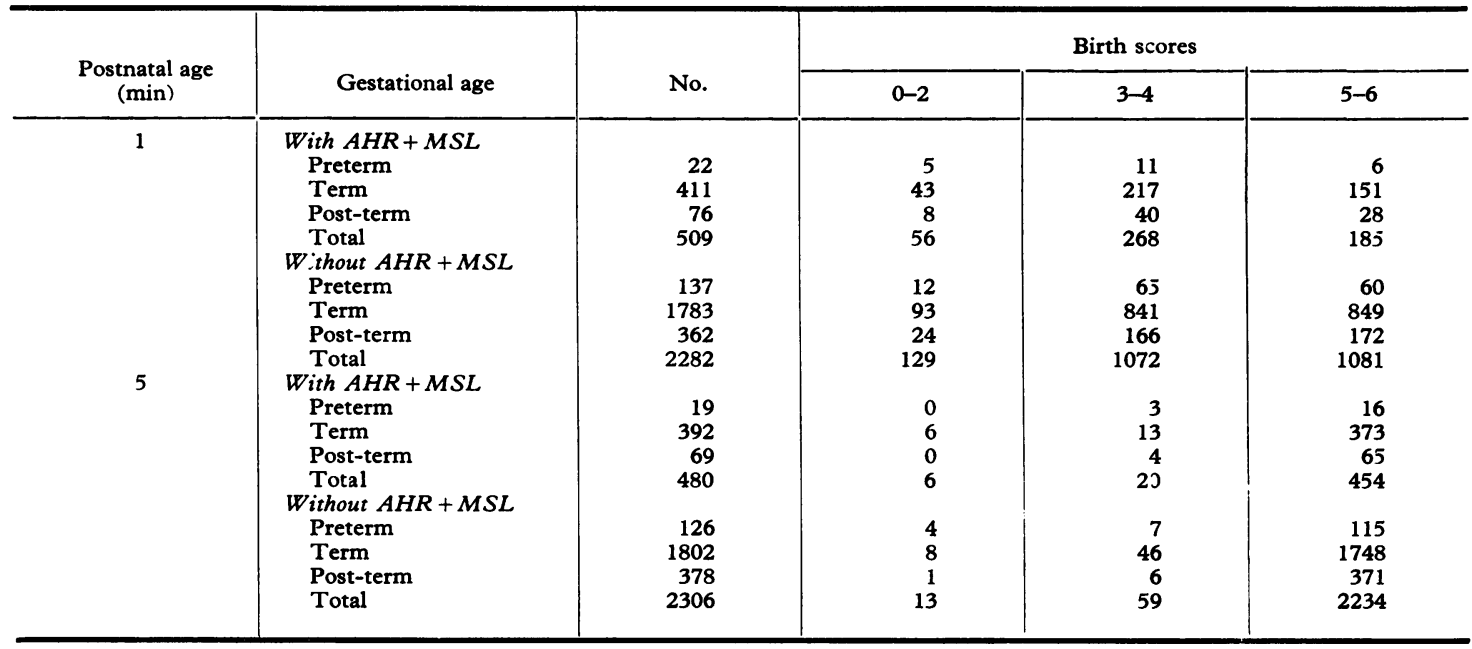

gasping, or regular; if the heart rate was undetectable, $<100$, or $>100 / \mathrm{min}$; and if the colour was white, blue, or pink. In addition, any infant who was brownskinned was noted. Therefore, a maximum score of 6 or a minimum of 0 was possible. Birth scores 0-4 were defined as low.

\section{Results}

The grouped birth scores of infants with or without fetal distress were compared after subdividing by gestational age.

Abnormal heart rate +meconium-stained liquor. Birth scores at 1 and 5 minutes after birth of infants with or without fetal distress are shown in Table I. If no allowance was made for gestational age there was a significant increase of low birth scores at the postnatal age of 1 minute $\left(P<0.001, \chi^{2}\right.$ test $)$ or 5 minutes $\left(P<0.05, \chi^{2}\right.$ test $)$ in those infants who had suffered fetal distress. When infants were subdivided into preterm, term, or post-term groups the difference was evident in the term group at 1 minute $\left(P<0.01, \chi^{2}\right.$ test $)$ and 5 minutes $\left(P<0.05, \chi^{2}\right.$ test $)$, but not in the preterm or post-term groups, possibly because of the small number of observations.

Effect of gestational age on birth score was then analysed after subdivision by the presence or absence of fetal distress. At the age of 1 minute there was no significant difference in the proportion of preterm, term, or post-term infarts with birth scores of $0-2,3-4$, or $5-6$, regardless of whether or not the infants had suffered fetal distress. In contrast, at 5 minutes of age among those with no fetal distress there was a greater proportion of preterm infants with low birth scores compared with the term or post-term infants.

The 93 term infants who did not have fetal distress but whose birth scores were 0-2 at 1 minute of age were investigated. Although drugs may have contributed to the low birth scores, it is unlikely that this was the sole cause since the pattern of drug administration to these 93 mothers was similar to that received by others in the study. Toxaemia was present in only 6 of the 93 mothers and only 2 of the 93 infants were small-for-dates; it is unlikely therefore that either of these factors played a major role in lowering birth scores. At 5 minutes, 69 of these infants had birth scores of $5-6$, and of the remaining 24 infants 20 had birth scores of 3-4 and 4 had scores $0-2$, indicating that most infants had recovered by 5 minutes of age. The outcome of the 93 infants was good in so far as no death or clinical abnormality occurred in the neonatal period.

Abnormal fetal heart rate. When abnormal heart rate was taken as the sole criterion of fetal distress there was a significantly greater proportion of infants with fetal distress who had a low score at 1 minute $\left(P<0 \cdot 001, \chi^{2}\right.$ test $)$ or 5 minutes $(P<0.01$, $\chi^{2}$ test), compared with those infants with no fetal distress (Table II). When subdivided by gestational 
TABLE II

Effect of gestational age on birth scores of infants with or without abnormal fetal heart rate (AHR)

\begin{tabular}{|c|c|c|c|c|c|}
\hline \multirow{2}{*}{$\begin{array}{c}\text { Postnatal age } \\
\text { (min) }\end{array}$} & \multirow[b]{2}{*}{ Gestational age } & \multirow[b]{2}{*}{ No. } & \multicolumn{3}{|c|}{ Birth scores } \\
\hline & & & $0-2$ & $3-4$ & $5-6$ \\
\hline 1 & $\begin{array}{l}\text { With } A H R \\
\text { Preterm } \\
\text { Term } \\
\text { Post-term } \\
\text { Total } \\
\text { Without } A H R \\
\text { Preterm } \\
\text { Term } \\
\text { Post-term } \\
\text { Total } \\
\text { With } A H R \\
\text { Preterm } \\
\text { Term } \\
\text { Post-term } \\
\text { Total } \\
\text { Without } A H R \\
\text { Preterm } \\
\text { Term } \\
\text { Post-term } \\
\text { Total }\end{array}$ & $\begin{array}{r}42 \\
635 \\
118 \\
795 \\
\\
117 \\
1559 \\
320 \\
1996 \\
42 \\
412 \\
109 \\
763 \\
\\
103 \\
1582 \\
338 \\
2023\end{array}$ & $\begin{array}{r}8 \\
62 \\
11 \\
81 \\
\\
9 \\
74 \\
21 \\
104 \\
0 \\
9 \\
0 \\
9 \\
4 \\
5 \\
1 \\
10\end{array}$ & $\begin{array}{r}21 \\
324 \\
63 \\
408 \\
\\
55 \\
734 \\
143 \\
932 \\
\\
5 \\
23 \\
5 \\
33 \\
5 \\
56 \\
5 \\
46\end{array}$ & $\begin{array}{r}13 \\
249 \\
44 \\
306 \\
\\
53 \\
751 \\
156 \\
960 \\
\\
37 \\
580 \\
104 \\
721 \\
\\
94 \\
1541 \\
332 \\
1967\end{array}$ \\
\hline
\end{tabular}

age the difference was still apparent at 1 minute in the term infants $\left(P<0.001, \chi^{2}\right.$ test) or post-term $\left(\mathrm{P}<0.005, \chi^{2}\right.$ test). There was no significant difference in the subgroups at 5 minutes of age.

When the infants were subdivided by the presence or absence of fetal distress there was, among those with no fetal distress, a significant increase in the proportion of preterm infants with low birth scores at 1 minute $\left(\mathrm{P}<0 \cdot 05, \chi^{2}\right.$ test $)$ or 5 minutes $\left(P<0 \cdot 001, \chi^{2}\right.$ test) when compared with term or post-term infants.

Meconium-stained liquor. When meconium stained liquor was taken as the sole index of fetas distress, a significantly greater proportion of alf infants suffering fetal distress had low birth scores? at 1 minute $\left(\mathrm{P}<0.01, \chi^{2}\right.$ test $)$ compared with those with no fetal distress (Table III). After sub-

TABLE III

Effect of gestational age on birth scores of infants with or without meconium-stained liquor (MSL)

\begin{tabular}{|c|c|c|c|c|c|}
\hline \multirow{2}{*}{$\begin{array}{l}\text { Postnatal age } \\
\text { (min) }\end{array}$} & \multirow[b]{2}{*}{ Gestational age } & \multirow[b]{2}{*}{ No. } & \multicolumn{3}{|c|}{ Birth scores } \\
\hline & & & $0-2$ & $3-4$ & $5-6$ \\
\hline 1 & $\begin{array}{l}\text { With } M S L \\
\text { Preterm } \\
\text { Term } \\
\text { Post-term } \\
\text { Total } \\
\text { Without } M S L \\
\text { Preterm } \\
\text { Term } \\
\text { Post-term } \\
\text { Total } \\
\text { With } M S L \\
\text { Preterm } \\
\text { Term } \\
\text { Post-term } \\
\text { Total } \\
\text { With iut } M S L \\
\text { Preterm } \\
\text { Term } \\
\text { Post-term } \\
\text { Total }\end{array}$ & $\begin{array}{r}83 \\
1174 \\
239 \\
1496 \\
76 \\
7020 \\
199 \\
1295 \\
\\
74 \\
1166 \\
249 \\
1489 \\
71 \\
71 \\
1028 \\
198 \\
1297\end{array}$ & $\begin{array}{r}10 \\
84 \\
21 \\
115 \\
\\
7 \\
52 \\
11 \\
70 \\
\\
2 \\
9 \\
0 \\
11 \\
\\
2 \\
5 \\
1 \\
8\end{array}$ & $\begin{array}{r}42 \\
597 \\
119 \\
758 \\
\\
34 \\
461 \\
87 \\
582 \\
\\
6 \\
31 \\
8 \\
45 \\
\\
4 \\
28 \\
2 \\
34\end{array}$ & $\begin{array}{r}31 \\
493 \\
99 \\
623 \\
\\
35 \\
507 \\
101 \\
643 \\
\\
66 \\
1126 \\
241 \\
1433 \\
\\
65 \\
995 \\
195 \\
1255\end{array}$ \\
\hline
\end{tabular}


TABLE IV

Composition of birth scores at 1 minute of age in infants with no abnormal fetal heart rates and meconiumstained liquor

\begin{tabular}{|c|c|c|c|c|c|c|c|}
\hline \multirow{2}{*}{ Gestational age } & \multicolumn{7}{|c|}{ Birth score } \\
\hline & 0 & 1 & 2 & 3 & 4 & 5 & 6 \\
\hline $\begin{array}{l}\text { Preterm } \\
\text { Term } \\
\text { Post-term } \\
\text { Preterm } \\
\text { Term } \\
\text { Post-term } \\
\text { Preterm } \\
\text { Term } \\
\text { Post-term } \\
\text { Preterm } \\
\text { Term } \\
\text { Post-term } \\
\text { Preterm } \\
\text { Term } \\
\text { Post-term }\end{array}$ & $\begin{array}{l}0 \\
1 \\
1\end{array}$ & $\begin{array}{cc}\mathbf{C} & \\
& 1 \\
& 0 \\
& 1 \\
\mathbf{1} & \\
\mathbf{1} & 1 \\
& 1 \\
& 2 \\
1\end{array}$ & $\begin{array}{r}\text { HR } \\
1 \\
5 \\
2 \\
\mathrm{CH}^{2} \\
9 \\
85 \\
19\end{array}$ & $\begin{array}{r}\text { HHR } \\
0 \\
1 \\
0 \\
\mathbf{C C H} \\
0 \\
3 \\
0 \\
\text { HHC } \\
2 \\
16 \\
3 \\
\text { HRC } \\
31 \\
224 \\
50\end{array}$ & $\begin{array}{c}\text { RRHH } \\
0 \\
1 \\
0 \\
\text { CCHH } \\
0 \\
2 \\
1 \\
\text { CCHR } \\
1 \\
4 \\
2 \\
\text { RRHC } \\
5 \\
38 \\
6 \\
\text { HHCR } \\
26 \\
552 \\
104\end{array}$ & $\begin{array}{c}\text { RRCCH } \\
4 \\
38 \\
7 \\
\text { HHCCR } \\
6 \\
67 \\
17 \\
\text { HHRRC } \\
20 \\
299 \\
53\end{array}$ & $\begin{array}{c}\text { RRCCHH } \\
30 \\
445 \\
95\end{array}$ \\
\hline
\end{tabular}

C, colour; $R$, respiration; $H$, heart rate.

dividing by gestional age, the difference was seen in term infants $\left(P<0.01, \chi^{2}\right.$ test) but not in preterm or post-term infants.

There was a significantly greater proportion of preterm infants with low birth scores at 5 minutes of age when compared with term or post-term infants among those who had suffered fetal distress $\left(P<0.05, \chi^{2}\right.$ test $)$ and those who had not $(P<0.01$, $\chi^{2}$ test).

Birth scores at 1 and 5 minutes of age. Tables IV and V show the detailed composition of the birth scores at 1 and 5 minutes of age in those infants with no fetal distress. In all three groups of infants colour was most often responsible for a birth score of 5 . Likewise, the loss of 1 unit each of colour and respiration was the commonest reason for a birth score of 4 . Scores of 3 or less were rare at 5 minutes of age and no conclusion may be drawn from them with confidence. At 1 minute of age, however, a score of 3 was made up commonly by the loss of 1 unit each of heart rate, respiration, and colour. Heart rate was the attribute best preserved and colour the one most easily lost.

Onset of fetal distress and its effect on mean birth scores. The number of mothers in whom clinical signs of fetal distress were present during labour is shown in the Fig. Meconium-stained liquor was present in 1496 (54\%) of 2791 mothers. In 987 of these mothers in whom meconiumstained liquor was the only sign of fetal distress the mean birth score of the infants was $4 \cdot 41 \pm 0.038$ (mean \pm SEM). An abnormal fetal heart rate also occurred in the remaining 509 mothers during labour and the mean birth score of their infants was $4 \cdot 05 \pm 0.056$. In $286(10 \%)$ of 2791 mothers, an abnormal fetal heart rate was the only manifestation of fetal distress and the mean birth score of their infants was $4 \cdot 24 \pm 0 \cdot 072$. No signs of fetal distress were detected in the remaining 1009 (36\%) mothers and the mean birth score of their infants was $4 \cdot 57 \pm 0 \cdot 037$. The step-by-step reduction in the mean birth scores, of approximately 0.2 at each stage, is significant with $P$ values ranging between 0.05 and 0.0001 ( $\mathrm{N}$-test). The progressive reduction in mean birth score in the presence of different clinical types of fetal distress was interpreted as indicating that meconiumstained liquor was an earlier sign than abnormal fetal heart rate.

\section{Discussion}

It is usual for the condition of infants at 1 and 5 minutes of age to be assessed by examining heart rate, colour, respiratory effort, muscle tone, and reflex irritability (Apgar, 1966). In the present 
TABLE V

Birth scores at 5 minutes of age in infants with no abnormal fetal heart rates and meconium stained liquor

\begin{tabular}{|c|c|c|c|c|c|c|}
\hline \multirow{2}{*}{ Gestational age } & \multicolumn{6}{|c|}{ Birth score } \\
\hline & 1 & 2 & 3 & 4 & 5 & 6 \\
\hline $\begin{array}{l}\text { Preterm } \\
\text { Term } \\
\text { Post-term } \\
\text { Preterm } \\
\text { Term } \\
\text { Post-term } \\
\text { Preterm } \\
\text { Term } \\
\text { Post-term } \\
\text { Preterm } \\
\text { Term } \\
\text { Post-term } \\
\text { Preterm } \\
\text { Term } \\
\text { Post-term }\end{array}$ & $\begin{array}{ll}\mathbf{H} & \\
& 1 \\
& 2 \\
& 0\end{array}$ & $\begin{array}{r}\text { HC } \\
3 \\
6 \\
1\end{array}$ & $\begin{array}{r}\text { HHC } \\
0 \\
2 \\
1 \\
\text { CCH } \\
1 \\
3 \\
0 \\
\text { HRC } \\
3 \\
8 \\
1\end{array}$ & $\begin{array}{r}\text { HHRR } \\
0 \\
1 \\
0 \\
\text { CCHH } \\
1 \\
3 \\
1 \\
\text { CCHR } \\
0 \\
5 \\
0 \\
\text { RRHC } \\
0 \\
5 \\
0 \\
\text { HHCR } \\
2 \\
19 \\
3\end{array}$ & $\begin{array}{c}\text { CCRRH } \\
0 \\
13 \\
0 \\
\text { HHCCR } \\
3 \\
19 \\
3 \\
\text { HHRRC } \\
2 \\
55 \\
6\end{array}$ & $\begin{array}{c}\text { CCRRHH } \\
110 \\
1661 \\
362\end{array}$ \\
\hline
\end{tabular}

C, colour; $R$, respiration; $H$, heart rate.

study the last two parameters were excluded because they could not be adequately assessed during the time available by the midwife. The omission of these two parameters, therefore, reduces inter- and intraobserver errors.

Although the three parameters contributing to birth scores in the present study are inter-related, infants do not always score equally on all three. Colour is usually the first to suffer when there is a drop in birth score, and heart rate may be recordable when infants score 0 for colour and respiration. The significance of each component of the Apgar score in terms of acid-base status of the infant has been studied by Crawford, Davies, and Pearson (1973) who reported that each component except colour correlated well with umbilical arterial $p \mathrm{H}^{\circ}$ $\mathrm{PCO}_{3}$, and base excess. The most informative set of components in respect of the acid-base state

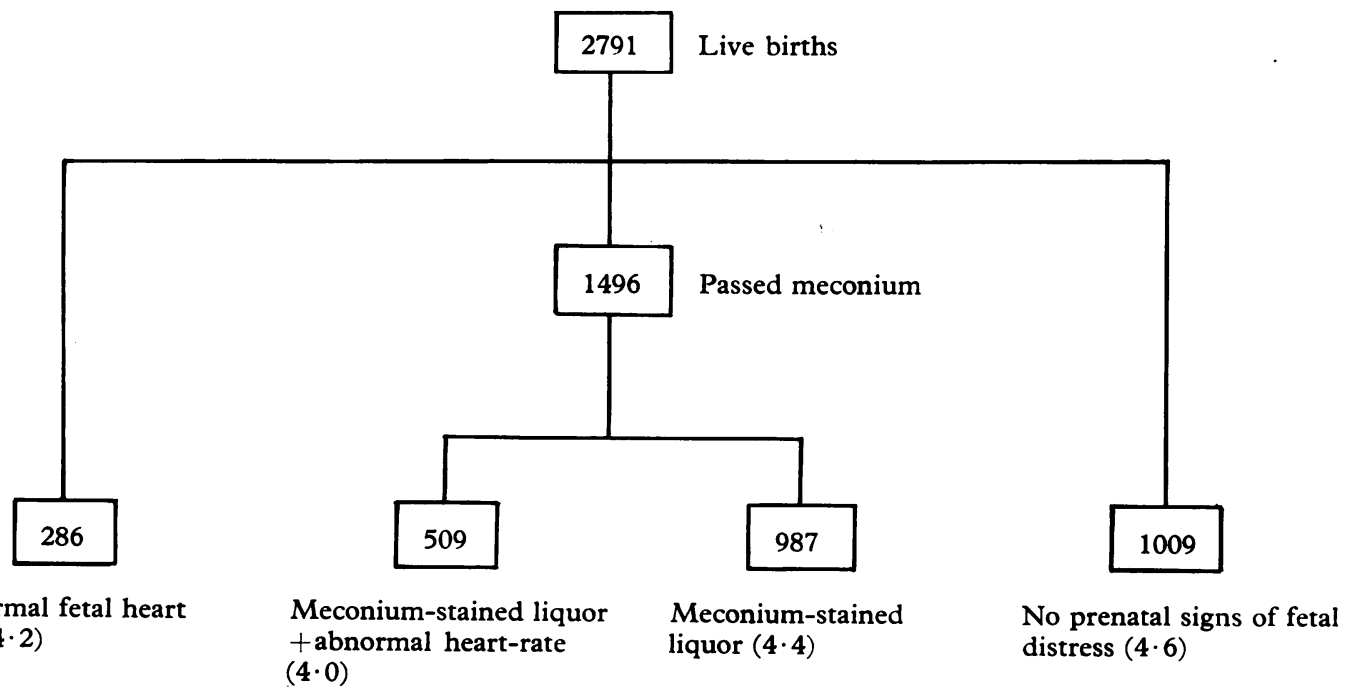

Abnormal fetal heart rate $(4 \cdot 2)$ +abnormal heart-rate $(4 \cdot 0)$

FIG.-Onset of fetal distress and its effect on mean birth score. Mean birth scores are in parentheses. 
of the infant were heart rate, muscle tone, and reflex irritability. It was suggested by these authors that colour should be disregarded because the score for colour could reduce the discriminatory value of the total score. However, this may be valid only with regard to colour as an indicator for the acid-base status of the newborn infant but not for other factors.

The proportions of preterm, term, and post-term infants with birth scores $0-6$ were similar in the presence of meconium-stained liquor plus abnormal heart rate. In the absence of this combination of signs there was an increase in the proportion of preterm infants with low birth scores at 5 minutes, though this finding was not statistically significant at 1 minute of age. There are similarities between this finding and those of the collaborative project studies of Drage and Berendes (1966). They reported an increase in the percentage of infants weighing less than $1501 \mathrm{~g}$ with low Apgar scores at 1 and 5 minutes of age compared with that in infants weighing $3001-3500 \mathrm{~g}$ or $4001 \mathrm{~g}+$. The similarity in birth scores between preterm and other infants in the presence of meconium-stained liquor plus an abnormal fetal heart rate is due to birth scores in the other infants being disproprotionately lowered.

It has been suggested that the passage of meconium is related to the maturity of the fetus or to fetal hypoxia and acidosis (Walker, 1959; Hobel, 1971; Tipton and Shelley, 1971). This leads one to think that the presence of meconium-stained liquor during labour, particularly in a premature fetus, is associated with deterioration in the condition of the fetus. Abramovici et al., (1974) concluded that the presence of meconium-stained liquor merely indicated a state of compensatory fetal distress since scalp blood $p \mathrm{H}$, fetal outcome, Apgar scores, or the number of interventions during delivery were similar in the presence of meconiumstained or clear liquor. They further suggested that a subsequent fall in scalp blood $p \mathrm{H}$ or change in heart rate indicated the end of this compensatory state. By contrast, in the present study, meconiumstained liquor was an early sign that the condition of the fetus had deteriorated during labour.

Present obstetric management has benefits for the mother in labour in terms of reducing pain and accelerating labour, but the risks of iatrogenic fetal asphyxia or acidosis have increased (Gordon, 1968; Teramo, 1969; Kubli and Rüttgers, 1971; Beard, 1974). The results of our study have shown that it is possible to diagnose fetal asphyxia when it occurs during labour in the majority of mothers by conventional methods. Nevertheless, in at least
93 mothers in whom there was no indication of fetal distress, the infants had birth scores of 0-2 at 1 minute of age. The introduction of sophisticated fetal monitoring techniques (Beard, 1974) are therefore necessary to enable the obstetrician to assess accurately the condition of the fetus during labour and to alert him whenever fetal asphyxia occurs.

The authors acknowledge a grant from the Nuffield Trust used for data collection; and thank Mrs. J. Cadman for computer programming work.

\section{REFERENCES}

Abramovici, H., Brandes, J. M., Fuchs, K., and Timor-Tritsch, I. (1974). Meconium during delivery: a sign of compensated fetal distress. American fournal of Obstetrics and Gynecology, $118,251$.

Adamsons, K., and Myers, R. E. (1973). Perinatal asphyxia: causes, detection and neurologic sequelae. Pediatric Clinics of North America, 20, 465.

Adamsons, K., Beard, R. W., and Myers, R. E. (1970). Comparison of the composition of arterial, venous and capillary blood of the fetal monkey during labour. American fournal of Obstetrics and Gynecology, 107, 435.

Apgar, V. (1966). The newborn (Apgar) scoring system. Pediatric Clinics of North America, 13, 645.

Beard, R. W. (1974). The detection of fetal asphyxia in labor. Pediatrics, 53, 157.

Beard, R. W., and Simons, E. G. (1971). Diagnosis of foetal asphyxia in labour. British fournal of Anaesthesia, 43, 874.

Born, G. V. R., Dawes, G. S., and Mott, J. C. (1956). Oxygen lack and autonomic nervous control of the foetal circulation in the lamb. Fournal of Physiology, 134, 149.

Crawford, J. S., Davies, P., and Pearson, J. F. (1973). Significance of the individual components of the Apgar score. British Fournal of Anaesthesia, 45, 148.

Dawes, G. S., Jacobson, H. N., Mott, J. C., and Shelley, H. J. (1960). Some observations on foetal and new-born rhesus monkeys. Fournal of Physiology, 152, 271.

Desmond, M. M., Moore, J., Lindley, J. E., and Brown, C. A. (1957). Meconium-staining of the amniotic fluid. Obstetrics and Gynecology, 9, 91.

Drage, J. S., and Berendes, H. (1966). Apgar scores and outcome of the newborn. Pediatric Clinics of North America, 13, 635.

Gordon, H. R. (1968). Fetal bradycardia after paracervical block. New England fournal of Medicine, 279, 910.

Hobel, C. J. (1971). Intrapartum clinical assessment of fetal distress. American Fournal of Obstetrics and Gynecology, 110, 336.

Hobel, C. J., Emmanouilides, G., Townsend, D. E., and Yashiro, K. (1970). Ligation of one umbilical artery in the fetal lamb; experimental production of fetal malnutrition. Obstetrics and Gynecology, 36, 582.

James, L. S., Morishima, H. O., Daniel, S. S., Bowe, E. T., Cohen, H., and Niemann, W. H. (1972). Mechanism of late deceleration of the fetal heart rate. American fournal of Obsterics and Gynecology, 113, 578.

Kubli, F. W., and Rüttgers, H. (1971). Iatrogenic fetal hypoxia. Physiology and Pathology in the Perinatal Period, p. 57. Ed. by R. H. Gevers and J. H. Ruys. Leiden University Press, Holland.

Kubli, F. W., Hon, E. H., Khazin, A. F. and Takemura, H. (1969). Observations on heart rate and $p \mathrm{H}$ in the human fetus during labor. American fournal of Obstetrics and Gynecology, 104, 1190

McCall, J. O., and Fulsher, R. M. (1953). A study of fetal distress, its interpretation and significance. American fournal of Obstetrics and Gynecology, 65, 1006.

Nesbitt, R. E. L. Jr. (1955). Prolongation of pregnancy: a review. Obstetric and Gynecology Survey, 10, 311. 
Schulte, M. (1925). The significance of the passage of meconium during labor. American foumal of Obstetrics and Gynecology, $10,83$.

Teramo, K. (1969). Studies on foetal acid-base values after paracervical blockade during labour. Acta Obstetricia et Gynecologica Scandanavica, 48, Suppl. 3, 80.

Tipton, R. H., and Shelley, T. (1971). An index of fetal welfare in labour. Fournal of Obstetrics and Gynaecology of the British Commonwealth, 78, 702.

Walker, J. (1959). Fetal distress. American Fournal of Obstetrics and Gynecology, 77, 94.
Wood, C., Ferguson, R., Leeton, J., Newman, W., and Walker, A (1967). Fetal heart rate and acid-base status in the assessment of fetal hypoxia. American fournal of Obstetrics and Gymecology, 88, 62.

Correspondence to [Dr. S. W. De Souza, University Department of Child Health, St. Mary's Hospital, Hathersage Road, Manchester M13 0JH. 